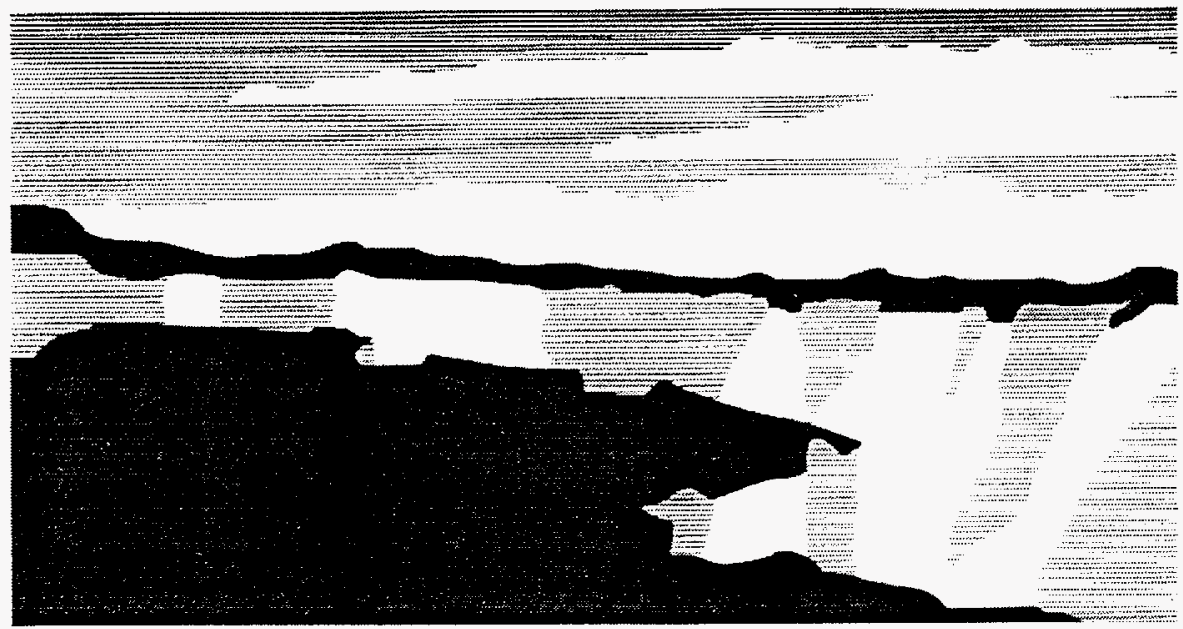

Los Alamos National Laboratory, an affirmative action/equal opportunity employer, is operated by the University of California for the U.S. Department of Energy under contract W-7405-ENG-36. By acceptance of this article, the publisher recognizes that the U.S. Government retains a nonexclusive, royaltytree license to publish or reproduce the published form of this contribution, or to allow others to do so, for U.S. Government purposes. The Los Alamos

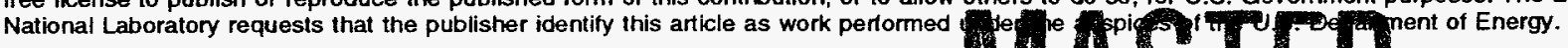




\section{DISCLAIMER}

Portions of this document may be illegible in electronic image products. Images are produced from the best available original document. 


\title{
Telemetric Heat Stress Monitor (THSM) Spin-Offs
}

Larry Berkbigler*, Orvil Bradley, Ricky Lopez, David Martinez, and Joseph Stampfer

\begin{abstract}
This is the final report of a one-year, Laboratory-Directed Research and Development (LDRD) project at the Los Alamos National Laboratory (LANL). This project sought to investigate spin-offs of the telemetric heat stress monitoring system (THSM) developed at LANL. Hazardous-materials workers and firefighters wear clothing that protects them from external hazards, but the sealed environment of a protective suit makes its wearer susceptible to heat stress. Heat stress occurs when the body's natural cooling mechanisms fail: it can cause collapse and death. The THSM warns both workers and remote monitoring personnel of incipient heat stress by monitoring and responding to elevations of workers' skin temperatures and heart rates. The technology won a 1994 R \& D 100 award.
\end{abstract}

\section{Background and Research Objectives}

Hazardous-materials workers and firefighters wear clothing that protects them from external hazards, but the sealed environment of a protective suit makes its wearer susceptible to heat stress. Heat stress occurs when the body's natural cooling mechanisms fail: it can cause collapse and death. The telemetric heat stress monitoring system (THSM) developed at LANL warns both workers and remote monitoring personnel of incipient heat stress by monitoring and responding to elevations of workers' skin temperatures and heart rates. The THSM was developed over the last three years; the engineering prototypes were successful and are currently used daily to support protective clothing development and evaluation activities at LANL. The THSM spin-offs investigated in this project were designed to enhance further the safety and effectiveness of hazmat workers. The THSM technology won a 1994 R \& D 100 award.

In this project we began investigating spin-offs to allow the THSM to be used for other applications in addition to monitoring personnel for heat stress. Our goal was to have a complete prototype that we could use to demonstrate two of those spin-offs -- protective suit breach detection and gas concentration sensing.

* Principal investigator, e-mail: lwb@lanl.gov 


\section{Importance to LANL's Science and Technology Base and National R\&D Needs}

This project supports Los Alamos core competencies in bioscience and biotechnology as well as earth and environmental systems. The THSM is most useful within DOE for the hazardous waste cleanup and accident response tasks. It also has large commercial markets in which there is currently no technology to meet the need. The project enhances the Laboratory's ability to respond to initiatives in sensor development.

\section{Scientific Approach and Resuits to Date}

We began by studying alternate approaches to the two spin-off applications and by surveying the market for sensors that could be applied to the problems. Early in the project, a significant amount of time was devoted to demonstrating the existing system to potential users and discussing their needs and additional applications. Personnel from the DOE, Navy, Army, Air Force, and AFL-CIO requested and were given demonstrations of the technology. A THSM prototype was constructed and tested for use when sensors became available.

The most significant new application is monitoring hazmat workers for breaches of protective clothing suits. This is obviously a great danger in most hazmat operations, but it can be very difficult to detect before it becomes a serious problem. Small aerosol monitors inside the clothing are the most promising sensors for breach detection, but aerosol content normally varies with time in an intact suit so the measurement will require processing to determine if a breach has occurred. Aerosol sensors were evaluated and a model was selected for the proofof-principle tests. In addition, pressure sensors were evaluated as an alternate breach detection sensor and appropriate models were purchased.

We conducted a survey of sensors for measuring explosive and poisonous gas concentrations outside the suit, but found none that are compatible with a small, low-power, continuously-operated device like the THSM. This technology area is rapidly advancing and will continue to be followed in hopes of finding new sensor candidates.

\section{DISCLAIMER}

This report was prepared as an account of work sponsored by an agency of the United States Government. Neither the United States Government nor any agency thereof, nor any of their employees, makes any warranty, express or implied, or assumes any legal liability or responsibility for the accuracy, completeness, or usefulness of any information, apparatus, product, or process disclosed, or represents that its use would not infringe privately owned rights. Reference herein to any specific commercial product, process, or service by trade name, trademark, manufacturer, or otherwise does not necessarily constitute or imply its endorsement, recommendation, or favoring by the United States Government or any agency thereof. The views and opinions of authors expressed herein do not necessarily state of reflect those of the United States Government or any agency thereof. 